\title{
Does Elevation Play a Role in the Transmission of Pulmonary Tuberculosis in South Africa?
}

Michael Rey, Samuel Alao and Benjamin Jacob*

Department of Global Health, College of Public Health, University of South Florida, Tampa, USA

\begin{abstract}
Pulmonary Tuberculosis is the number one killer in South Africa. Although this is helped spurred on by the HIVIAIDS co-epidemic. We explored the effect of elevation in Tuberculosis transmission and mortality. Landsat 8 imageries were downloaded through earth-explorer and processed in Arc map 10.3. LULC maps generated from the satellite images were used for land characterization of provinces in South Africa. 3D DEM in Arc scene was utilized in displaying the elevation dataset. Our findings on the aggregate data at the provincial level could not show the association between elevation and Tuberculosis transmission and mortality.
\end{abstract}

Keywords: Land use; Land cover; Digital elevation model; Tuberculosis

\section{Introduction}

Although South Africa ranks just sixth in the world for a total number of Tuberculosis cases it has the second highest incidence rate of any country, with rates just barely lower than Lesotho [1]. According to the South African government, nearly $1 \%$ of the population of the country contracts Tuberculosis annually, with the number of newly reported cases having risen undeviatingly from 1999 until 2010 when new cases had a slight decrease [2]. To make matters worse, the South African government released that the highest estimated prevalence rate of the latent Tuberculosis infection was around $88 \%$ was recorded in the age group 30-39 years in the dense populated urbanized areas [2].

Altitude has been known for some time to have an almost curing effect on those infected with the pulmonary disease, like Tuberculosis, and altitude therapy in mountain hospitals and clinics were used strictly to help cure the sick of their ailments in the early 1800s [3]. One studies found that if a person infected with Tuberculosis travels to an elevated area that there is no difference in the antimycobacterial immunity they would have at sea-level, proving the old trend wrong [4]. There have been recent studies, however, have found conflicting results on whether or not altitude of an individual infected with pulmonary Tuberculosis or the elevation of a settlement plays a role in either helps cure the infection or further aids the transmission it. Though multiple researchers have in fact used elevation as part of their studies of Tuberculosis transmission as a covariable, none have looked at elevation as a prime contributing factor.

One thing that most of these Tuberculosis studies have in common, however, is that study sites at higher elevations did report having lower positive TST results. It is unclear whether or not the elevation of the test sites is to blame for this or possibly another confounding factor, but should be taken into consideration regardless.

\section{Methods and Materials}

\section{Site description}

South Africa is located in the southern-most portion of the African continent neighbored by Namibia, Botswana, and Zimbabwe to the north and surrounded by Atlantic and Indian Oceans to the west and east. South Africa has a total land area of approximately 1,221,037 $\mathrm{km}^{2}$. As of 2011 the country had a population of $51,770,560$ people, $80.2 \%$ were Black, $8.8 \%$ were Coloured, $8.4 \%$ were White, and $2.5 \%$ were Asian, and had a population density of $42.4 / \mathrm{km}^{2}$. South Africa has 11 official languages, each of them spoken and understood differently throughout the country. Among these are Afrikaans (the most widely used), English, Northern and Southern Sotho, Southern Ndebele, Swazi, Tsonga, Tswana, Venda, Xhosa, and Zulu. South Africa has a current 2016 estimated GDP (PPP) of \$ 742.461 billion and GDP per capita of $\$ 13,321$ [5]. South Africa is considered by many experts to be an anomaly amongst the world of developing and developed countries, as the country itself has well developed infrastructure but also has many economic and social issues plaguing it. In terms of the Human Development Index (HDI) of 0.666 indicated medium levels of life expectancy, education, and income per capita [6]. To further emphasize what this fact, the South African Institute of Race Relations estimated that in 2009 the average life expectancy of a white South African was 71 compared to only 48 for a black South African [7]. This gap in life expectancy between both races has occurred due to the HIV/ AIDS epidemic, that largely effects the black population. South Africa also scores a 63.1, a fairly high value, as a Gini coefficient indicating a large amount of inequality within the country [8]. However, South Africa is unique due to the fact that each of its nine provinces all differs from each other in some way; whether its climate, demographics or geography.

The Northern Cape is South Africa's least populace province with a population of just 1,162,900 people and has a sparse population density of just $3.1 / \mathrm{km}^{2}$. Of this number $50.4 \%$ are Black African, $40.3 \%$ are Coloured, $7.1 \%$ are White, and $0.07 \%$ are either Indian or Asian [9]. The Northern Cape is, however, the country's largest province in terms of land area, occupying $125,754 \mathrm{~km}^{2}$ of territory. The Northern Cape has 5 official languages Afrikaans spoken at $53.8 \%$, Tswana spoke at $33.1 \%$, Xhosa is spoken at 5.3\%, English spoken at $3.4 \%$, and Sotho spoken by $1.3 \%$ [9]. It is estimated that around $68 \%$ of the Northern

${ }^{*}$ Corresponding author: Benjamin Jacob, Department of Global Health, College of Public Health, University of South Florida, Tampa, USA, Tel: 8139742011; E-mail: bjacob1@health.usf.edu

Received November 04, 2016; Accepted December 08, 2016; Published December 09, 2016

Citation: Rey M, Alao S, Jacob B (2016) Does Elevation Play a Role in the Transmission of Pulmonary Tuberculosis in South Africa? J Remote Sensing \& GIS 5: 184. doi: 10.4182/2469-4134.1000184

Copyright: $\odot 2016$ Rey M, et al. This is an open-access article distributed unde the terms of the Creative Commons Attribution License, which permits unrestricted use, distribution, and reproduction in any medium, provided the original author and source are credited. 
Cape's population know Afrikaans as their first language. The Northern Cape relies heavily on both the mining and agriculture sectors, which employs nearly $57 \%$ of all provincial employees. Although tis province does have a coastline most of the province itself is actually located 850 meters above sea level, with the south and south-east portions lying around 1,200-1,900 meters above sea level. Most of the center areas of the Northern Cape are relatively flat with salt plains spread throughout, and the northern most reaches of the province are mostly covered by the Kalahari Desert. This province has a predominately arid to semi-arid climate and has an average annual rainfall of just $202 \mathrm{~mm}$ (8.0 in) [10]. Most areas experience extreme heat, with the hottest recorded temperatures measured near the Namibian border. In the summer, most areas experience temperatures of around $30^{\circ} \mathrm{C}$ $\left(86^{\circ} \mathrm{F}\right)$ or greater, and sometimes hotter than $40^{\circ} \mathrm{C}\left(104^{\circ} \mathrm{F}\right)$. The winter months are generally cold and clear, with some of the southern areas of the province receiving snow and temperatures below $-10^{\circ} \mathrm{C}\left(14^{\circ} \mathrm{F}\right)$. In the Northern Cape, the Tuberculosis incidence rate is 875 cases per 100,000 people, and the Tuberculosis mortality rate was 88 deaths per 100,00 cases [11].

The Eastern Cape is South Africa's second largest province in terms of land area, encompassing nearly $168,966 \mathrm{~km}^{2}$ of territory. Compared to the Northern Cape, however, the Eastern Cape has nearly six times the number of people with a population of 6,562,053 and a population density of $39 / \mathrm{km}^{2}$ [9]. $86.3 \%$ of this population are Black African, $8.3 \%$ Coloured, $4.7 \%$ are White, and $0.4 \%$ are Indian or Asian [9]. The Eastern Cape only has four official languages, these of which are Xhosa is spoken by $78.8 \%$ of people, Afrikaans spoke by $10.6 \%$ of people, English is spoken by $4.7 \%$ of people, and Sotho which is spoken by $2.5 \%$ of people. Similar to the Northern Cape, the Eastern Cape's economy is heavily dependent upon the agriculture industry due to its vast amounts of fertile land but this province is also dependent upon the industrial sector as well where two major manufacturing cities, Port Elizabeth and East London, have huge automotive factories. The Eastern Cape has a maximum elevation at $3,019 \mathrm{~m}(9,905 \mathrm{ft}$.) and its lowest point being at sea-level on the coastlines, with most of its territory lying in the 850-950 $\mathrm{m}$ range. This province has a highly-varied climate with the western areas being dry with hot summers and frosty winter, the eastern areas are plentiful in rainfall and have a very humid subtropical climate along the coast, and the interior receives very heavy amounts of snow. The Eastern Cape has a Tuberculosis incidence rate of 589 cases per 100,000 people and a Tuberculosis mortality rate of 87 deaths per 100,000 cases [11].

Free State, or formerly known as Orange Free State, is South Africa's third largest province in terms of land area, totaling 129,825 $\mathrm{km}^{2}$ of territory. This province has a population of $2,745,590$ people living at a density of $21 / \mathrm{km}^{2}$ [9]. Free State's population is composed of $87.1 \%$ Black African, $8.7 \%$ White, 3.1\% Coloured, and $0.4 \%$ Indian or Asian. This province is the only one in South Africa where the most common language spoken is Sotho at $64.2 \%$, but still, has Afrikaans spoken and understood widely throughout at $12.7 \%$. Xhosa was spoken at $7.5 \%$, Tswana was spoken at $5.2 \%$, Zulu was spoken at $4.4 \%$, and English was spoken by only $2.9 \%$ [9]. Free State's economy is more varied than the first two provinces with key sectors being agriculture, mining, industry such as chemical manufacturing, and tourism. This province is characterized by its continental climate, one with warm to hot summers and cool to cold winters. Eastern areas of Free State experience frequent snowfalls especially on the higher ranges, while the western portions experience extremely hot summers. Most of the province is high- lying with the majority of its territory being above $1,000 \mathrm{~m}(3,2801 \mathrm{ft}$.) above sea-level, and the provinces highest point being 3,291 m (10,797 ft.) above sea-level. Free State has a Tuberculosis incidence rate of 643 cases per 100,000 people and a Tuberculosis mortality rate of 99 deaths per 100,000 cases [11].

The Western Cape province of South Africa is situated towards the south-western portion of the country. It is the fourth largest of the all nine provinces in South Africa in terms of both population and land area, housing roughly 5,822,734 people in a total area of $129,462 \mathrm{~km}^{2}$ [9]. This province has a population density of $45 / \mathrm{km}^{2}$. The Western Cape's population is comprised of $48.8 \%$ Coloured, $32.8 \%$ Black African, $15.7 \%$ White, and $1.0 \%$ of Indian or Asian. Of these people 49.7\% of them speak Afrikaans, $24.7 \%$ speak Xhosa, and 20.2\% speak English [9]. The Western Cape's economy is the second largest in South Africa and contributes to nearly $14 \%$ of the country's total GDP [12]. It is also one of the fastest growing economies in South Africa growing at a $4 \%$ rate in 2008 and another $3.2 \%$ in 2011 [12]. The biggest economic sector of this province is financial and business services, and tied for second largest would be agriculture and manufacturing. Topographically, the Western Cape is very diverse with its highest peak being at 2,325 $\mathrm{m}(7,628 \mathrm{ft}$.) and its coastlines being at sea-level, but most areas vary in height from $1,000 \mathrm{~m}$ to around 2,000 $\mathrm{m}$. The Western Cape is also very climatologically diverse, with many different microand macroclimates which are influenced by both ocean currents and the varied topography. Most of the province, however, is considered to have a Mediterranean climate having cool wet winters and warm, dry summers. Some interior areas of the province have a semiarid to arid with hot summers and cold, frost winters. Some southern areas, such as Mossel Bay, have very mild maritime climates. The Western Cape has a Tuberculosis incidence rate of 911 cases per 100,000 people and a Tuberculosis mortality rate of 40 deaths per 100,000 cases [11].

Despite its name, the Northern Cape is not actually the northern most province of South Africa, the province of Limpopo actually is Limpopo is located to the most north-eastern corner of South Africa and shares its northern-most borders with Zimbabwe, Botswana, and Mozambique. This province has a total land area of $125,754 \mathrm{~km}^{2}$ and is home to a population of $5,404,868$ people living at a density of $43 / \mathrm{km}^{2}$ [9]. The population of this province is comprised of $96.7 \%$ Black African, $2.6 \%$ White, $0.3 \%$ Indian or Asian, and 0.3\% Coloured. Limpopo is another province where the Sotho language is spoken predominately at $52.9 \%$, while Tsonga is spoken by $17.0 \%$, Venda is spoken at $16.7 \%$, and Afrikaans is spoken by only $2.6 \%$ [9]. Limpopo is South Africa's poorest province, with more than $78.9 \%$ of the population living below the national poverty line [13]. Limpopo's economy is heavily based on mining, agriculture, and tourism, which provides around $11 \%$ of the province's revenue [14]. Limpopo has quite a hot tropical climate, due to the fact that it is bisected by the tropic of Capricorn with long, hot summers and cool winters [15]. Most of Limpopo's territory sits at an elevation of around 950-1,000 m, with some of the highest areas reaching well over $1,500 \mathrm{~m}$. Limpopo has a Tuberculosis incidence rate of 249 cases per 100,000 people and a Tuberculosis mortality rate of 62 deaths per 100,000 cases [11].

The North West province of South Africa is located southwest of Limpopo and shares a border to the north with Botswana. It has a population of 3,509,953 people living in an area of $104,882 \mathrm{~km}^{2}$ at a density of $33 / \mathrm{km}^{2}$ [9]. Of this population; $89.9 \%$ identify as Black African, $7.3 \%$ identify as White, $2.0 \%$ identify as Coloured, and $0.6 \%$ identify as Indian or Asian. These groups of people speak five official languages with Tswana spoken at $63.4 \%$, Afrikaans spoke at $9.0 \%$, Sotho spoken by $5.8 \%$, Xhosa spoken at $5.5 \%$, and Tsonga spoke at $3.7 \%$ [9]. The main pillar of the North west province's economy is 
mining, generating more than half of its GDP and employs nearly half of its workforce. The North West forms the southern part of the Kalahari Desert, giving the province nearly year-round sunshine and hot temperatures ranging between 22 and $34^{\circ} \mathrm{C}$ in the summer and 2 to $20^{\circ} \mathrm{C}$ in the winter [16]. This province's territory is very highlying with most of the land well above $1,200 \mathrm{~m}$ above sea-level and its highest point being at $1,805 \mathrm{~m}$ (5,922 ft.). North West province has a Tuberculosis incidence rate of 637 cases per 100,000 people and a Tuberculosis mortality rate of 84 deaths per 100,000 cases [11].

KwaZulu-Natal is South Africa's eastern most province and shares its borders with southern Mozambique and the Indian Ocean. Roughly the size of Portugal, KwaZulu-Natal has a land area of $94,361 \mathrm{~km}^{2}$ and is home to $10,267,300$ people [9]. This province has a population density of $110 / \mathrm{km}^{2}$ making it the second most densely populated province in South Africa. $88.6 \%$ of the province's inhabitants identify as Black African, 7.4\% identify as Indian or Asian, $4.2 \%$ identify as White, and $1.4 \%$ Identify as Coloured. KwaZulu-Natal is the only province that has a majority of Zulu speakers at $77.8 \%$, while English is spoken by $13.2 \%$, Xhosa is spoken by 3.4\%, and Afrikaans is spoken by $1.6 \%$ [9]. This province has many different aspects of its economy, each varying heavily depending on location. The city of Durban is one of South Africa's busiest ports in the country and is responsible for much of the sugar refining in the country. In the northern city of Newcastle, synthetic rubber manufacturing is the name of the game, and off the shores mining for heavy mineral sands and fishing of prawns contribute heavily to KwaZulu-Natal's GDP [17]. The climate of KwaZulu-Natal is quite varied due to its complex and diverse topography, with coastlines usually being subtropical and inland areas progressively getting colder. This province has a very diverse topography, with most of its territory laying in the $200-1,000 \mathrm{~m}$ range with the highest regions reaching well into the 2,000-3,000 m range above sea-level. KwaZulu-Natal has a Tuberculosis incidence rate of 907 cases per 100,000 people and a Tuberculosis mortality rate of 81 deaths per 100,000 cases [11].

Mpumalanga is the province just north of KwaZulu-Natal and has a population of 4,039,939 people living in a land area of $76,495 \mathrm{~km}^{2}$ [9]. This province is the third densest in South Africa, having a population density of $53 / \mathrm{km}^{2}$. The population of Mpumalanga identifies as $90.7 \%$ Black Africa, $7.5 \%$ White, $0.9 \%$ Coloured, and $0.7 \%$ Indian or Asian. This province has 5 official languages with Swati, the official language of neighboring Swaziland, spoken at $27.7 \%$, Zulu spoke at $24.1 \%$, Tsonga spoken at $10.4 \%$, Ndebele spoken at $10.1 \%$, and Northern Sotho spoke by $9.3 \%$ [9]. The mainstay of the Mpumalanga economy lies in agriculture, in which nearly $68 \%$ of the province is used for [18]. Other important sectors are extensive heavy mineral mining, and tourism to national parks. The climate of Mpumalanga is mainly subtropical in the southern regions of the province, due to its latitude and proximity to the Indian Ocean, and generally much cooler in the northern regions due to a high elevation above sea-level. Most of Mpumalanga's territory is situated above the $1,500 \mathrm{~m}$ above the sealevel mark, with the province's highest point being at 2,331 $\mathrm{m}(7,648 \mathrm{ft}$. $)$ above sea-level. Mpumalanga has a Tuberculosis incidence rate of 416 cases per 100,000 people and a Tuberculosis mortality rate of 80 deaths per 100,000 cases [11].

Gauteng is South Africa's smallest province in terms of land area, with only $18,178 \mathrm{~km}^{2}$ of territory, however, it is also the country's most populace and densely populated province with $12,272,263$ people living at a density of $680 / \mathrm{km}^{2}$ [9]. In the 2011 census, the population of Gauteng identified as $74.1 \%$ Black African, 19.1\% White, 3.5\% Coloured, and 2.26\% Indian or Asian. This province has five official languages, with
Zulu spoken at $17.8 \%$, English is spoken by $14.3 \%$, Afrikaans spoken at $13.8 \%$, Sotho spoke by $11.6 \%$, and Northern Sotho spoke by $10.6 \%$ [9]. Gauteng's economy is one of the busiest and most varied in South Africa contributing heavily to many sectors such as manufacturing, transportation, financial, technology, and telecommunications sectors. This province is also responsible for providing the country with nearly a third of its GDP [19]. From a latitude perspective, Gauteng should have a subtropical climate but due to its elevation, the climate is generally cooler. Most of the province's territory lies above $1,300 \mathrm{~m}$ above selevel with some of its cities located at $1,700 \mathrm{~m}$ above sea-level. Gauteng has a Tuberculosis incidence rate of 372 cases per 100,000 people and a Tuberculosis mortality rate of 49 deaths per 100,000 cases [11].

Most materials used for this study were from online sources and then used inside specific programs. Landsat 8 30-meter satellite imagery of South Africa was collected via the United States Geological Survey's (USGS) online program "EarthExplorer". 77 image files were collected in total, each covering an area of $111 \times 10^{6}$ miles. ArcMap 10.3.1 was then used to mosaic all of the Landsat data into one seamless image so it could be converted into composite band data to be used in a maximum likelihood classification for a Land Use Land Cover (LULC) map. The classification created a Land Use Land Cover map overlay showing urban and non-urban areas, as well as farmland, and waterbodies throughout the country of South Africa.

The Land Use Land Cover map was used to differentiate between urban and non-urban areas, farmlands, mining areas, and waterbodies (Figure 1). The urban areas in this study were defined as any area encompassing a small to a large number of people living in relatively close proximity to one another in any form of permanent settlement. This classification included areas from the largest cities and shanty towns to small towns and villages. Any area that fell under the nonurban category was defined as any area with no permanent or informal human settlement that excluded water. Farmlands were categorized and defined as any large acreage plantations to small subsistence farm plots. This category differed from urban areas because a very large majority of farmlands were located outside or urbanized zones, and therefore the risk of spreading pulmonary Tuberculosis would be very slight. In this study, waterbodies were defined as any body of water ranging from coastlines that surround South Africa to lakes, rivers, ponds, and streams.

ArcMap 10.3.1 was also used to calculate the maximum, minimum, and mean elevation data that was used in a Linear Regression calculation later on in this study. By taking nine Digital Elevation Model (DEM) files, one for each province, and creating a zonal statistics table for each the minimum, maximum, and mean elevation for all nine provinces was calculated. Elevation data (highest point, lowest point, and mean elevation) was collected in order to create a comparison between provinces and was then used in a regression model to determine if there was a correlation between the elevation data collected and the Tuberculosis incidence and mortality rates. This was done due to a prior study conducted in Mexico using similar elevation statistics as South Africa, where the outcome was that as the altitude of an urbanized area decreases so will the mortality rate of Tuberculosis [20].

ArcScene 10.3.1 was then used to construct the $3 \mathrm{~d}$ models showing all the elevation data of South Africa (Figure 2). The DEM images were floated using the data in their respective attribute tables to rise the image from a 2-dimensional layer into a 3-dimensional landscape of each province. The models were generated for each of the nine provinces, and a scale was implemented to show elevation in meters, with dark blue indicating the lowest lying areas and dark red indicating the highest-lying areas. 
Citation: Rey M, Alao S, Jacob B (2016) Does Elevation Play a Role in the Transmission of Pulmonary Tuberculosis in South Africa? J Remote Sensing \& GIS 5: 184. doi: 10.4182/2469-4134.1000184

Page 4 of 7
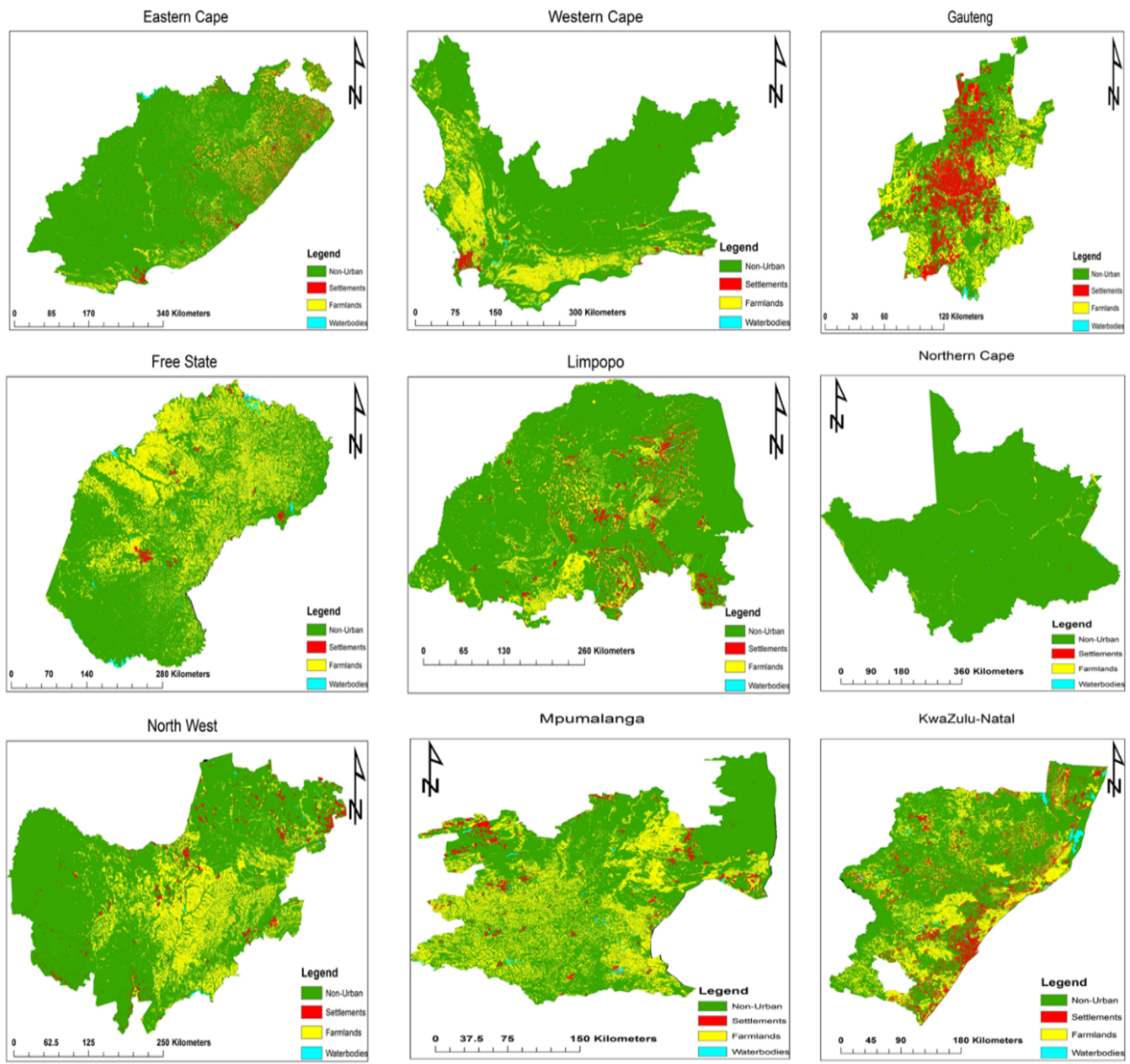

Figure 1: The Land Use Land Cover map to differentiate between urban and non-urban areas, farmlands, mining areas, and waterbodies.

Microsoft Excel 2015 was used to record all numerical data which included provincial population, provincial population density, Tuberculosis mortality and incidence rates, and the provincial elevation data (Table 1). SAS 9.4 was used to input the provincial data from the Excel CSV file where elevation data, population data, and Tuberculosis data were collected and saved to. After the data was inputted into SAS a negative binomial regression model was generated using the data from the Excel CSV file. After the regression, had been run and the model was generated, the data was then analyzed with a chi-squared test.

Population and population density were both collected from 2011 census information [9], total land area for each province was shown in kilometers squared $\left(\mathrm{km}^{2}\right)$, elevation data (minimum, maximum, and mean) were all expressed in meters, and mortality rates and pulmonary
Tuberculosis cases per province were both collected from the 20122016 National Strategic Plan for South Africa [2].

\section{Results}

Based on results retrieved from the negative binomial regression (Figure 3), there was not a statistically significant enough p-value to determine that elevation is a key factor in aiding the transmission of pulmonary Tuberculosis in South Africa.

\section{Limitations}

As one can easily tell, there are in fact many limitations when using data collected strictly at the provincial level. With there only being nine provinces in South Africa there was not enough data to create a highly accurate regression on. Using data that was only geo-referenced at the 
Citation: Rey M, Alao S, Jacob B (2016) Does Elevation Play a Role in the Transmission of Pulmonary Tuberculosis in South Africa? J Remote Sensing \& GIS 5: 184. doi: 10.4182/2469-4134.1000184

Eastern Cape

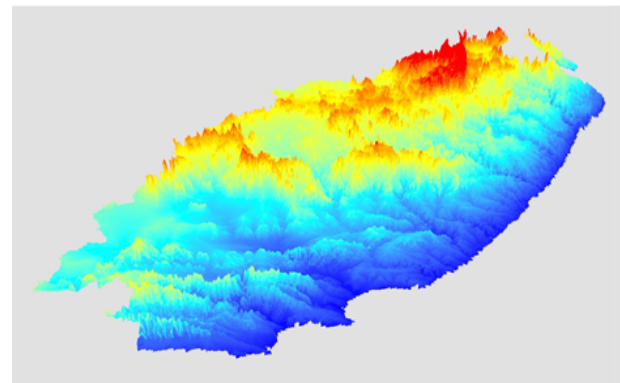

Free State

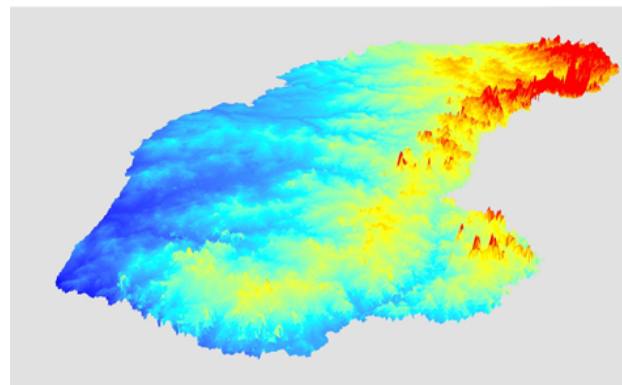

North West
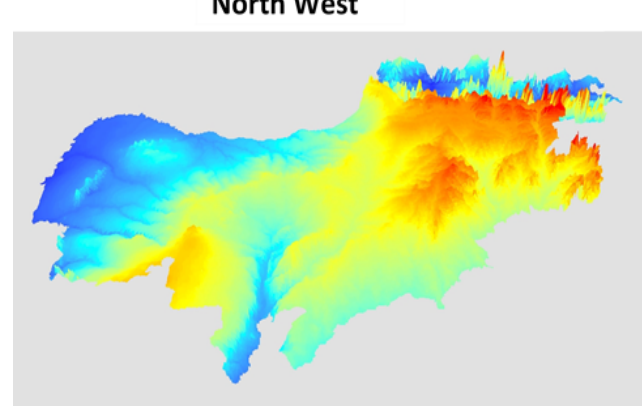

Western Cape

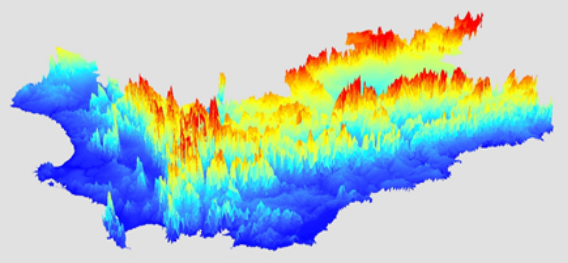

Limpopo
Gauteng

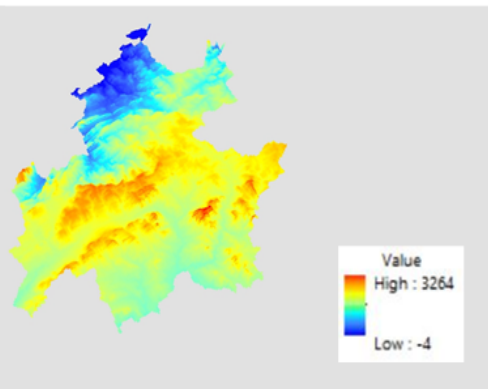

Northern Cape

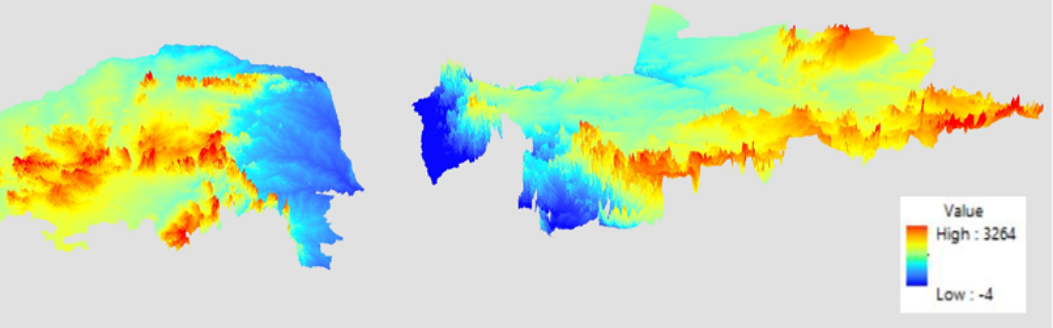

Mpumalanga

KwaZulu-Natal
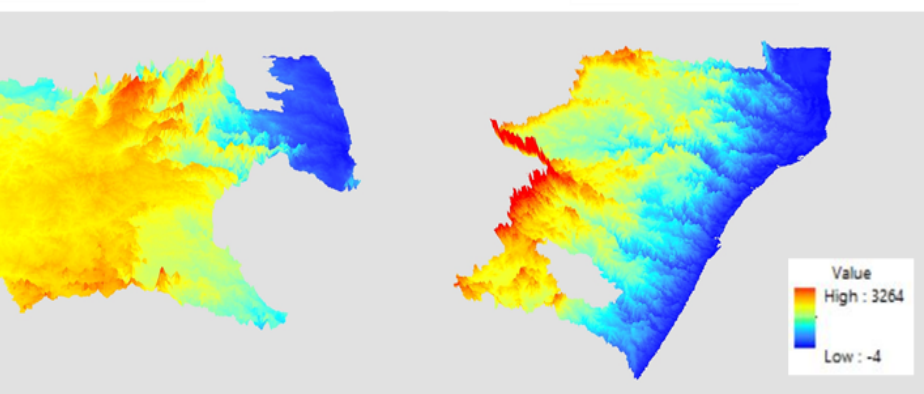

Figure 2: $3 \mathrm{~d}$ models showing all the elevation data of South Africa.

\begin{tabular}{|c|c|c|c|c|c|c|c|c|}
\hline Province & Pop & Pop Den & Area & Min_Elev & Max_Elev & Mean_Elev & Mortality & PTB_Cases_per_100000 \\
\hline Limpopo & 5404868 & 43 & 125755 & 112 & 2019 & 1028.06 & 62 & 249 \\
\hline Western Cape & 5822734 & 45 & 129462 & 0 & 2172 & 990.48 & 40 & 911 \\
\hline Eastern Cape & 6562053 & 38.8 & 168966 & 1 & 2920 & 1364.98 & 87 & 589 \\
\hline Northern Cape & 1145861 & 3.1 & 372889 & 1 & 2063 & 966.34 & 88 & 875 \\
\hline Free State & 2745590 & 21.1 & 129825 & 1083 & 3057 & 1727.15 & 99 & 643 \\
\hline North West & 3509953 & 33.5 & 104882 & 927 & 1734 & 1319.35 & 84 & 837 \\
\hline Mpumalanga & 4039939 & 52.8 & 76495 & 126 & 2281 & 1168.88 & 80 & 816 \\
\hline KwaZulu-Natal & 10267300 & 108.8 & 94361 & -4 & 3264 & 1377.19 & 81 & 907 \\
\hline Gauteng & 12272263 & 675.1 & 18178 & 954 & 1889 & 1399.88 & 49 & 372 \\
\hline
\end{tabular}

Table 1: Numerical data which included provincial population, provincial population density, Tuberculosis mortality, incidence rates, and the provincial elevation data. 
Citation: Rey M, Alao S, Jacob B (2016) Does Elevation Play a Role in the Transmission of Pulmonary Tuberculosis in South Africa? J Remote Sensing \& GIS 5: 184. doi: 10.4182/2469-4134.1000184

Page 6 of 7

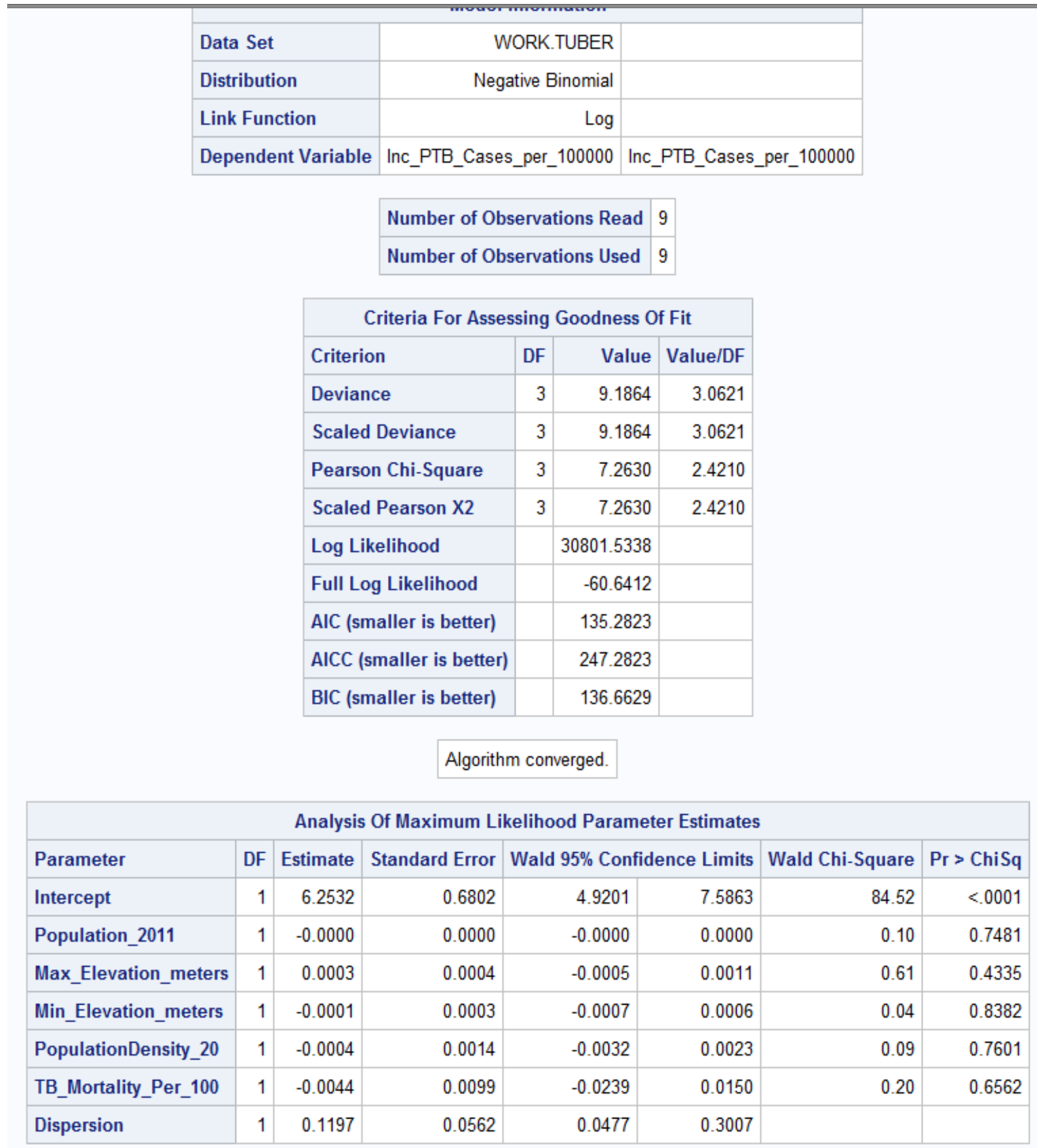

Figure 3: Results retrieved from the negative binomial regression.

provincial level was also a contributing limiting factor of this study, as only so much can be interpreted by the population density, elevation, and incidence and mortality rates of Tuberculosis within such a large area. Also Tuberculosis mortality rates and incidence rates data would have proven more effective if there were no gaps in years of data collected by South African census data, which prevented a seamless timeline of accurate and reliable numbers to be used in the regression model. Elevation data may have also played a role as a limiting factor due to the fact that the highest and lowest points of each province were all collected using ArcMap DEM files that had to be clipped to the shape of each province. This may have caused some slight errors in number that might have possibly effected the regression model's results as well. This regression also did not take socioeconomic factors into consideration, as elevation was the only independent variable that was looked at during this study.

\section{References}

1. World Health Organization (2015) Global Tuberculosis Report 2015. 20th edn WHO Library, Geneva, Switzerland, pp: 1-192.

2. Republic of South Africa (2016) National Strategic Plan on HIV, STIs, and TB 2012-2016. South African National AIDS Council, South Africa, pp: 1-29. 
Citation: Rey M, Alao S, Jacob B (2016) Does Elevation Play a Role in the Transmission of Pulmonary Tuberculosis in South Africa? J Remote Sensing \& GIS 5: 184. doi: 10.4182/2469-4134.1000184

3. Rogers FB (1969) The rise and decline of the altitude therapy of tuberculosis. Bull Hist Med 43: 1-16

4. Eisen S, Pealing L, Aldridge RW, Siedner MJ, Necochea A, et al. (2013) Effects of Ascent to High Altitude on Human Antimycobacterial Immunity. PLoS ONE 8: e74220

5. IMF (2016) South Africa: International Monetary Fund. Communications Department, Washington DC, USA.

6. Selim J (2016) Human Development Report 2015. United Nations Development Programme, Washington DC, USA.

7. Dimakatso M (2011) Peoples Budget Coalition Comments on the 2011/12 Budget. The Human Sciences Research Council, South Africa.

8. World Bank Group (2016) Gini Index: World Bank.

9. Statistics South Africa (2012) Census 2011: Census in brief. National Library of South Africa, Pretoria Division, Pretoria, South Africa.

10. Dent MC, Lynch SD, Schulze RE (1987) Mapping Mean Annual and Other Rainfall Statistics over Southern Africa. Water Research Commission, Petoria, South Africa.

11. WHO (2009) TB Impact Measurement: Policy and recommendation for how to assess the epidemiological burden of TB and the impact of TB control. World Health Organization, Geneva, Switzerland.
12. Western Cape government (2016) Western Cape economy with Alan Winde Ministry of Agriculture, Economic Development and Tourism, Cape Town South Africa.

13. (2016) Living condition. Statistics South Africa.

14. Matambo OK (2010) 2010 Budget Speech. Department of Economic Development, Environment and Tourism, Government Printing and Publishing Services, Gaborone, Botswana.

15. South Africa Limpopo (2015) The Climate of Limpopo Province. South Africa Channel, South Africa.

16. South Africa Venues (2015) North West Province Weather and Climate. South Africa Travel News, 16. South Africa.

17. Global Home (2016) Richards Bay Minerals: History. Rio Tinto Limited Melbourne, Australia.

18. South Africa Information Gateway (2016) Mpumalanga in brief: The economy of the province. South African Government, South Africa.

19. GEDA (2016) Gauteng Province. Gauteng Economic Development Agency, Marshall town, South Africa.

20. Pérez-Padilla R, García-Sancho C, Fernández R, Franco-Marina F, LópezGatell H, et al. (2013) The impact of altitude on hospitalization and hospital mortality from pandemic 2009 influenza A (H1N1) virus pneumonia in Mexico. Salud Pública De México 55: 92-95 